\title{
The Classic
}

\section{Elbow and Shoulder Lesions of Baseball Players*}

\author{
George E. Bennett MD (1885-1962) \\ The 8th President of the AAOS 1939
}

George Eli Bennett was born in Claryville, NY, in the Catskill Mountains, in 1885 [3]. His parents both died by the time he was 11 , leaving him the need to work while going to school, but he excelled in school and sports. He played semipro baseball at the age of 16. After high school he work in various jobs in the Midwest before he could afford to attend the University of Maryland Medical School, from which he graduated in 1908. At the age of 25 in 1910, he joined the staff at the Johns Hopkins Hospital, where he remained until his resignation in 1947.

Dr. Bennett was one of a few men who served as President of both the American Orthopaedic Association and the American Academy of Orthopaedic Surgeons. While Dr. Bennett made many contributions to orthopaedic surgery, including children's and nonoperative orthopaedics, he was best known for his work in sports medicine (undoubtedly related to his being a gifted athlete). His fame extended well beyond the orthopaedic community, for he treated many famous athletes. Sports Illustrated recognized him upon his death in an article entitled, "Mender of Immortals" [4]. His intimate knowledge of sports undoubtedly contributed to his sage judgments. At an emotional dinner in 1958 many famous athletes sometimes tearfully paid tribute to Dr. Bennett. Joe Garagiola commented on the occasion, "After listening to that all-star team of players Dr. Bennett has mended, I'm sorry I didn't break my leg" [4].

Among Dr. Bennett's many publications, including those related to sports, we have chosen one [2] of two articles $[1,2]$ he wrote on elbow and shoulder problems in baseball players. He described the now well-known degenerative changes and periarticular calcific deposits that occur in the elbows and shoulders of pitchers. Some of

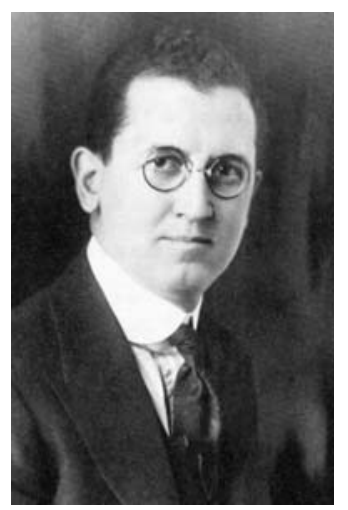

Dr. George Bennett is shown. Photograph is reproduced with permission and (C)American Academy of Orthopaedic Surgeons. Fifty Years of Progress, 1983.

these, he suggested, were not symptomatic and he advised against treatment. Dr. Bennett commented, however, "Since professional athletes are human beings, not supermen, general health often plays a part in the disability and should be the first thought in the mind of the examiner" [2].

Richard A. Brand MD

\section{References}

1. Bennett GE. Shoulder and elbow lesions of the professional baseball player. JAMA. 1941;117:510-514.

2. Bennett GE. Elbow and shoulder lesions of baseball players. Am J Surg. 1959;98:484-492.

3. George Eli Bennett. J Bone Joint Surg Am. 1962;44:1711-1713.

4. Scorecard. Mender of immortals. Sports Illustrated. July 30,1962:7. 
(C) The Association of Bone and Joint Surgeons 2008

(The Classic Article is reprinted from The American Journal of Surgery, Vol 98, Bennett GE, Elbow and Shoulder Lesions of Baseball Players, pages 484-492, (C)1959, with permission from Elsevier.)

*Professor of Orthopaedics (Emeritus) Johns Hopkins Medical School, Baltimore, Maryland.

Eighteen years have elapsed since my first article on elbow and shoulder disabilities of ball players was published [1] and as I read it I find I have not changed my opinion as to diagnosis, clinical findings and treatment. Since I do not believe 1 can express my opinions in more lucid terms I shall make a number of direct quotations.

On many occasions I have been asked to designate the type or lesion that is disabling to the professional baseball player. My answer has always been that the baseball player is subject to the same disabilities of the shoulder and elbow as the average person, namely subacromial and subdeltoid bursitis, irritation of the supraspinatus, irritation of the biceps tendon, traumatic synovitis and all the inflammatory diseases. Needles to say, because of his professional activities disability of shoulder and elbow occurs more frequently in the ball player than in one not engaged in an occupation which requires such excessive physical use of these articulations.

Since professional athletes are human beings, not supermen, general health often plays a part in the disability and should be the first thought in the mind of the medical examiner. Frequently, infected teeth or tonsils cause or aggravate the irritated joints. Lesions of the inflammatory group respond to removal of infection and to an improved general health regimen.

\section{Elbow}

Shands [3] proved conclusively that trauma to hyaline cartilage produced a definite hyperplasia. The margins and the tip of the olecranon and the adjacent surfaces of the condyles of the humerus are constantly traumatized by the throwing of a baseball. The result produces a definite osteochondritis with exfoliation of cartilage which may produce loose bodies, synovial thickening or semiattached cartilagenous masses which obstruct and limit the extension of the elbow. This is the most common lesion seen in baseball players (Figs. 1 and 2). In the presence of pain, swelling and disability which is prolonged, the lesions respond well to removal. If the lipping of the cartilage of the olecranon and the condyles is marked, these structures can be removed. In many instances this lesion exists without symptoms, or only intermittent transient discomfort, and should not be removed.
Richard A. Brand MD ( $\square)$

Clinical Orthopaedics and Related Research, 1600 Spruce Street, Philadelphia, PA 19103, USA

e-mail: dick.brand@clinorthop.org

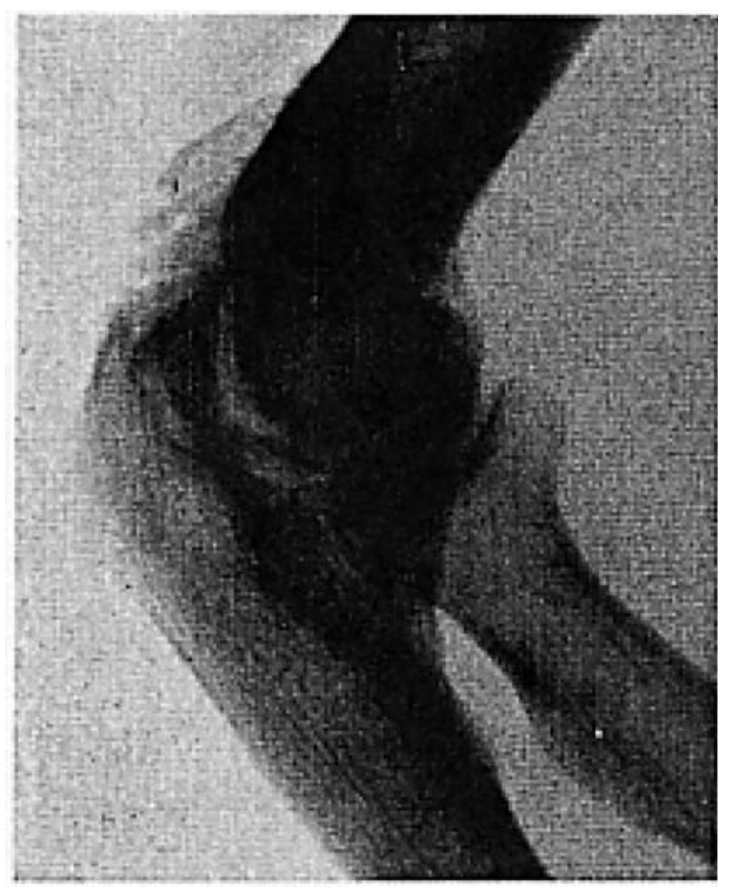

Fig. 1 Osteochrondritis of the olecranon.

\section{Olecranon Fractures}

Fractures of the olecranon are not frequent. I recall only four instances, two of which occurred in young athletes, and both happened in batting. The weight of the bat assisted in extending the elbow to such a degree that a small chip fracture resulted. Operation and removal of the detached piece of bone gave prompt relief (Fig. 3).

The third case was a rather unusual fracture which occurred when a player, whose normal position was first base, was assigned to the outfield. When making the long hard throw, he had sudden pain and immediate disability (Fig. 4). Roentgenographic examination disclosed that the fracture was due to a marked deformity and elongation of the olecranon, probably the result of an injury in childhood. The fracture was wired and the player returned to active play. It was believed that his olecranon would fracture again unless the elongated and deformed tip was removed. My associate (Dr. E. McDonnell) removed a generous portion of the olecranon and reattached the triceps. The player states that his arm is stronger and that he can throw 
Fig. 2 Osteochrondritis of the olecranon and loose bodies.

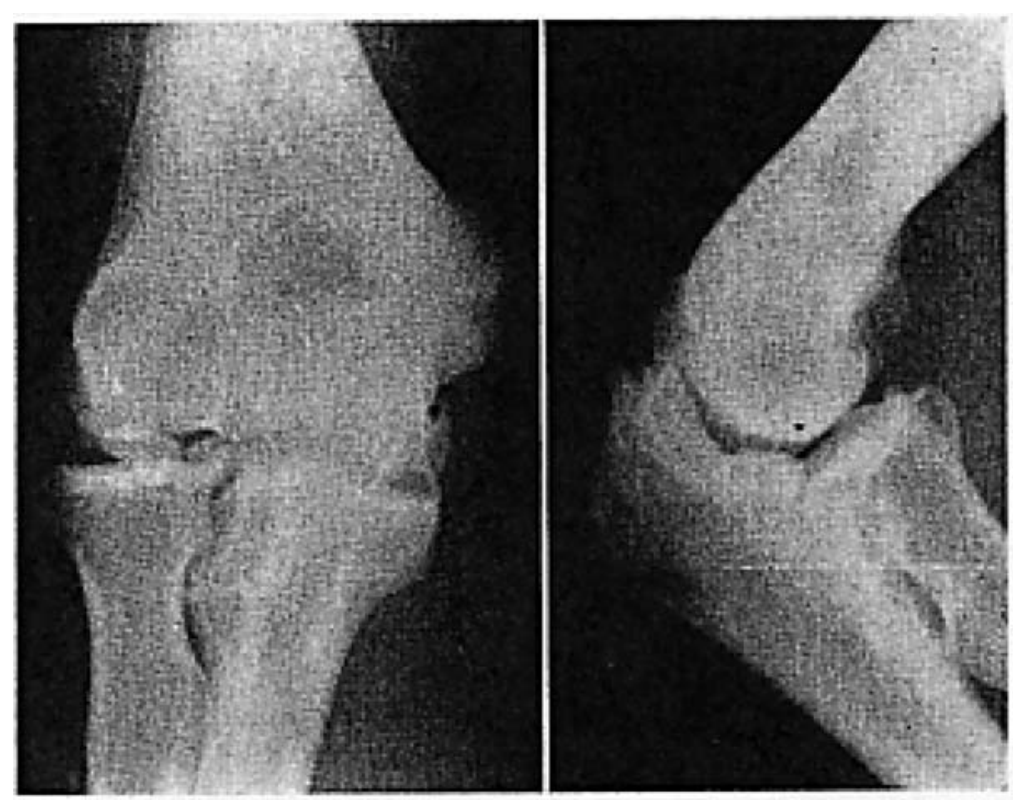

Fig. 3 Chip fracture of the olecranon from batting.

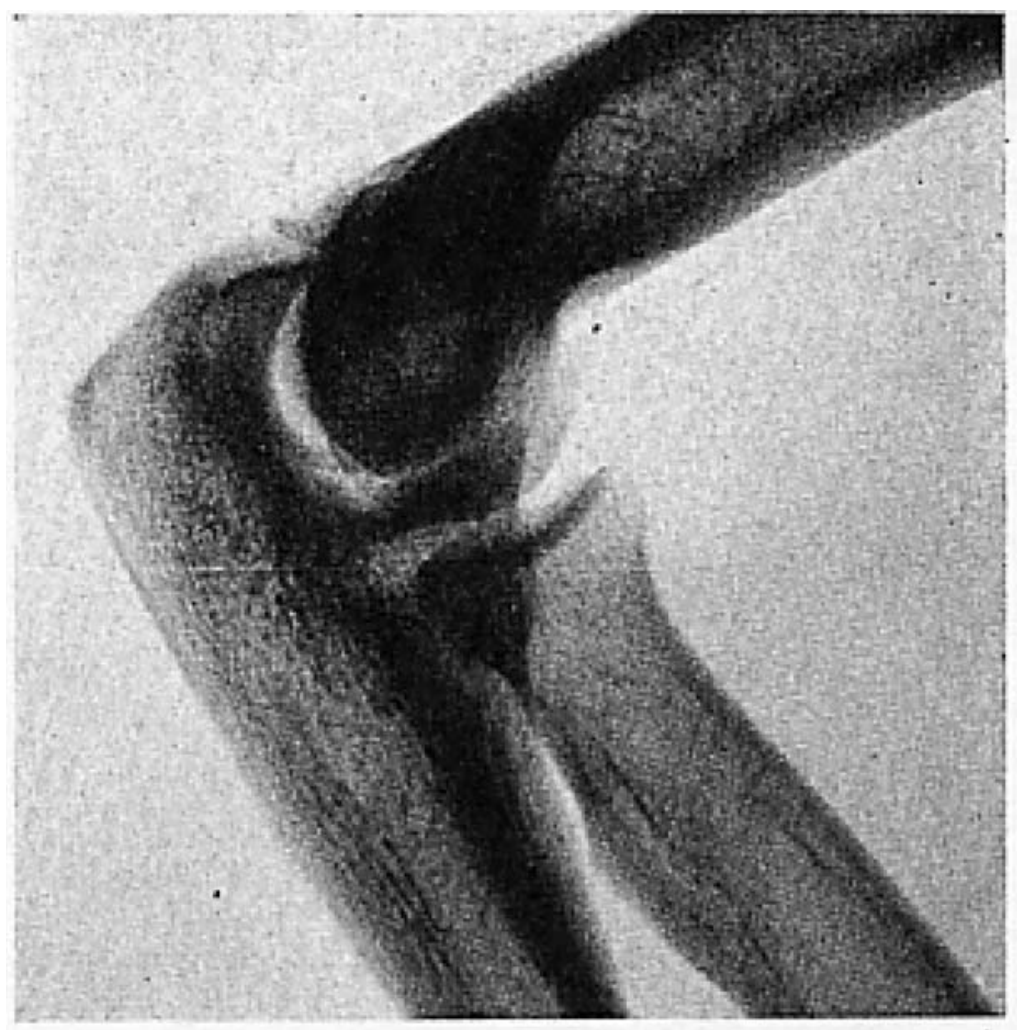

harder than at any time in the past. He is one of the best first basemen in the American League.

The fourth case is a curious one. I must theorize as to the etiology and have made no definite plan as to treatment except to await results. I have advised rest. In this young catcher, without history of trauma, the elbow of his throwing arm gradually became painful. Roentgenographic examination disclosed a pathologic condition which to me is similar to fatigue or march fracture in the foot (Fig. 5).

\section{Spurs}

A sharpening and spur formation of the articulation between the internal condyle of the humerus and the ulna is 


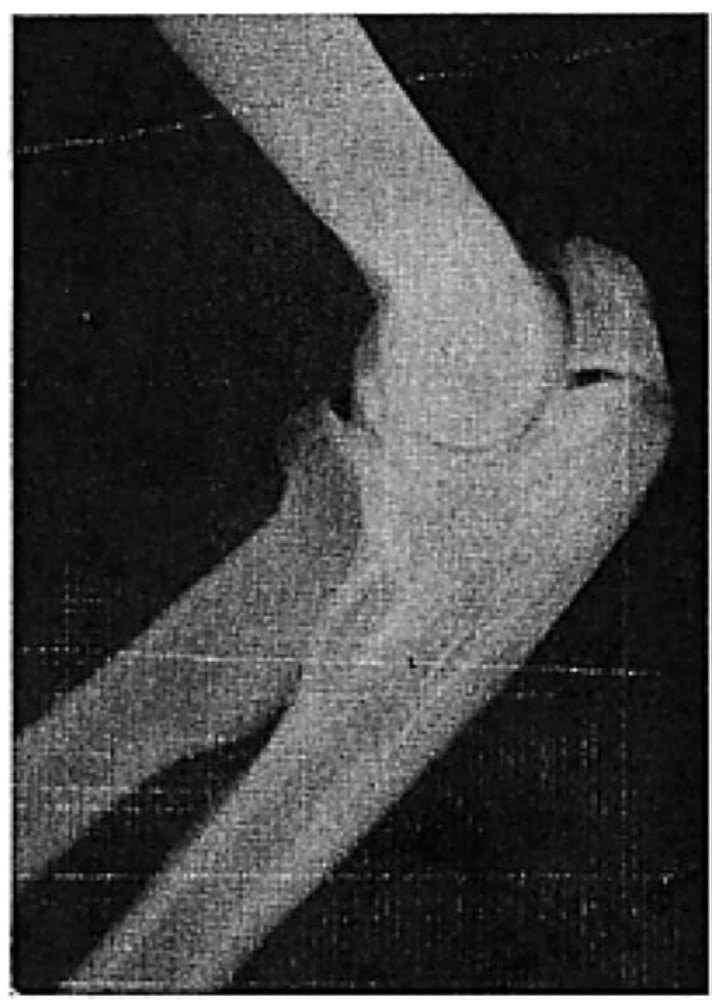

Fig. 4 Deformity of the olecranon predisposing fracture from throwing a baseball.

frequent and often transient. At times, however, it is necessary to remove the spurs in rather young ball players.

It is curious how closely these spurs present the same clinical picture that is seen in spurs of the os calcis. Very often these spurs are so small that they are difficult to visualize in the X-ray film. However, they are extremely painful.

In contrast to this, one often sees very large exostoses which are painless. Two examples are demonstrated in Figures 6 and 7. The left-handed pitcher in Figure 8 consulted me regarding a definite shoulder lesion. He also presented the common loss of extension of the elbow. Routine roentgenogram demonstrated the huge exostosis which was symptomless; surgery was not performed.

The second case was that of a veteran pitcher in whom a progressive disability had developed and who, for the past year, was unable to throw a baseball hard. It is quite obvious that this exostosis took years to develop. Surgery was performed and he had several active years in baseball. (Fig. 9.) One can see the progressive development of these exostoses in Figures 6 through 9.

There is a lesion which produces a different syndrome. A pitcher in throwing a curve ball is compelled to supinate his wrist with a snap at the end of his delivery. This movement plus extension leads to the development of an irritation in front of and below the internal condyle of the

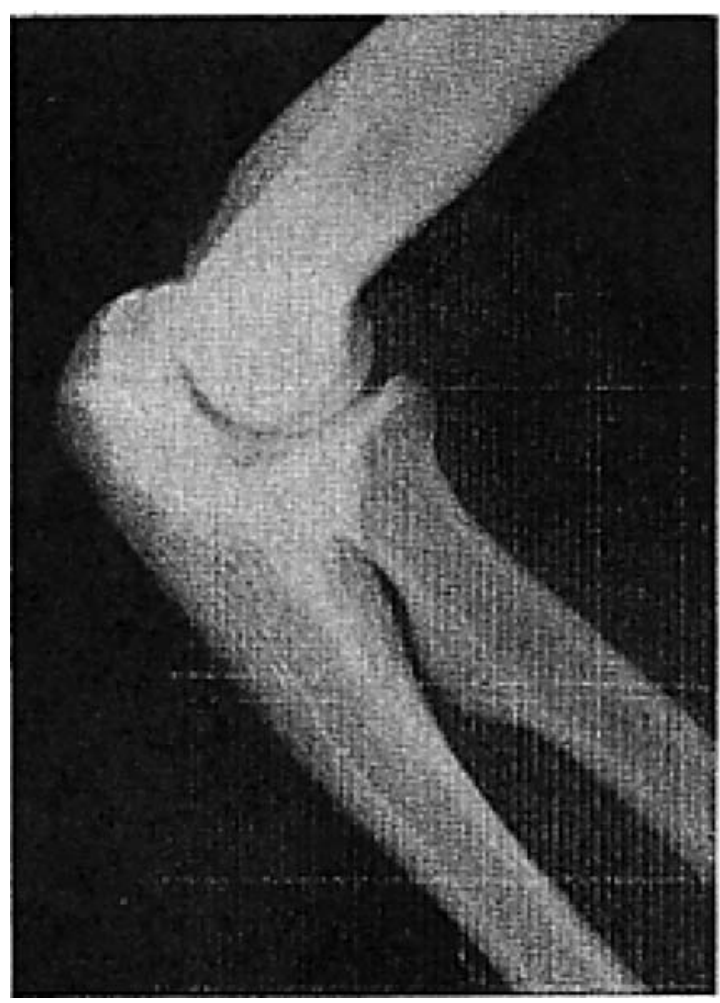

Fig. 5 Fatigue fracture of the olecranon.

humerus which is extremely disabling. On examination one will note distinct fullness over the pronator radii teres, beneath which are the tendinous attachments of the brachialis and the flexor sublimis digitorum. These are covered by a strong fascial band, a portion of which is the attachment of the biceps, which runs obliquely across the pronator muscle. A pitcher may be able to pitch for two or three innings but then pain and swelling become so great that he has to retire. Roentgenograms in the majority of cases are entirely within normal limits, and my experience shows that exploration of the joint reveals no pathology and, therefore, is not advised. The muscle tissue generally is normal in appearance. A simple linear and transverse division of the fascia covering the muscles has relieved tension on many occasions and rehabilitated these men so that they were able to return to the game. I am at a loss to explain it except that tension develops from some unidentified irritation to the muscle tissue, or it is quite possible that this may be secondary to an irritation of the ulna at its articulation with the internal condyle.

\section{Deposits of Bone or Ossicles}

A distinctive lesion, and one which is not seen in other occupations, is the development of single or multiple deposits of bone or ossicles in the ligamentous tissue and tendinous attachments beneath the ulnar nerve and not 


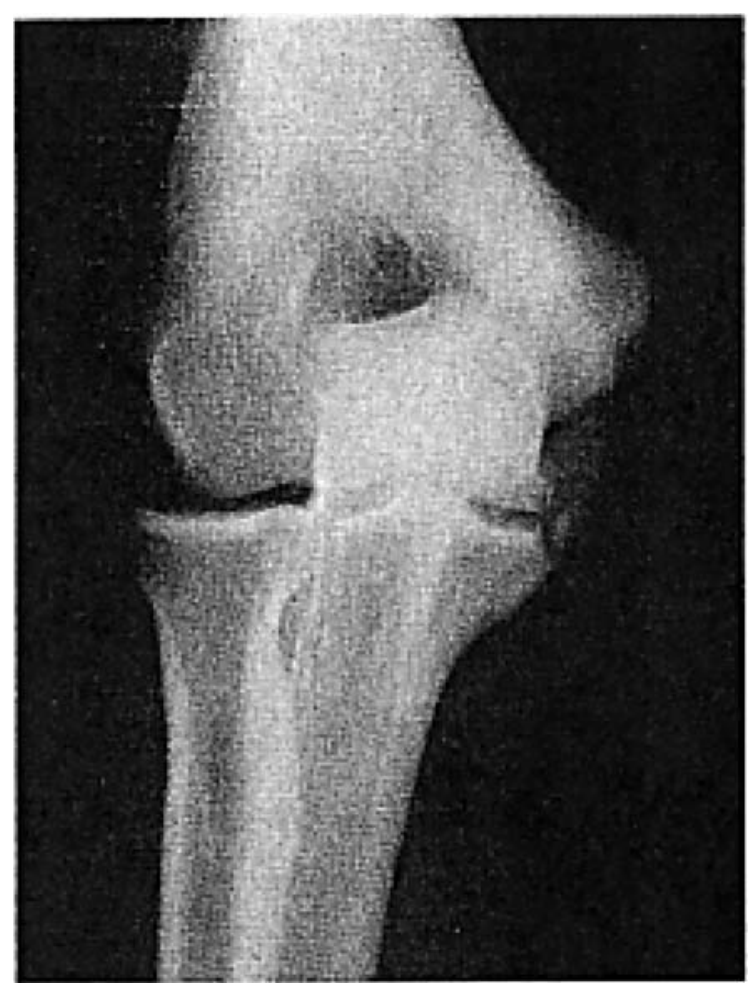

Fig. 6 Small spur formation of the internal condyle of the ulna.

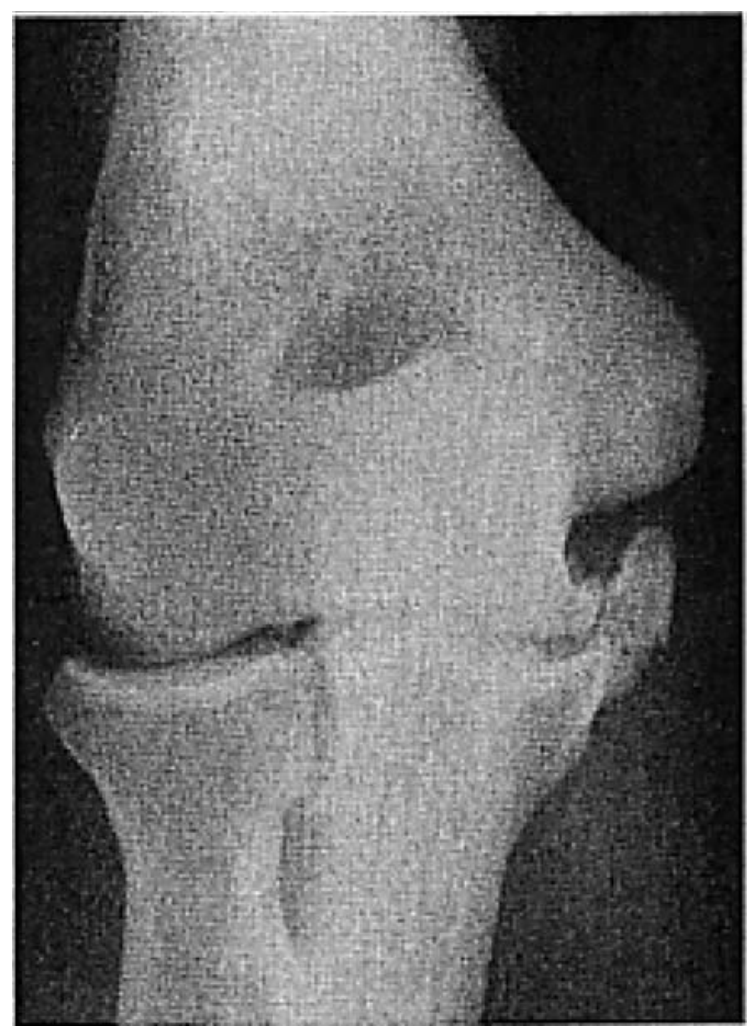

Fig. 8 Large spur of the internal condyle of the ulna.

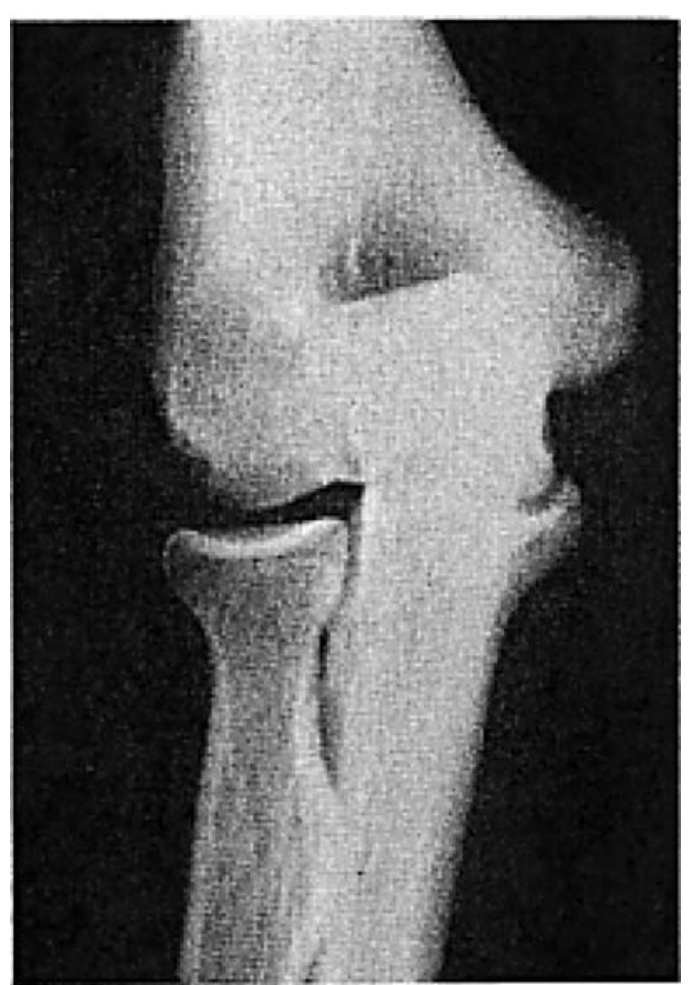

Fig. 7 Progressive development of spur.

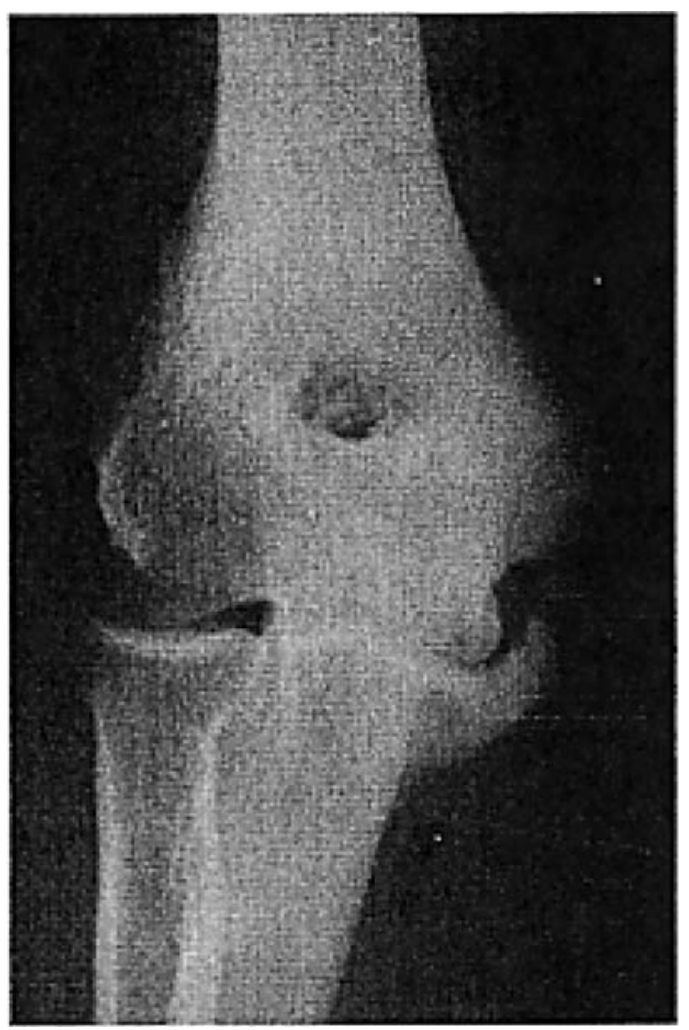

Fig. 9 Large spur with ossicle. 


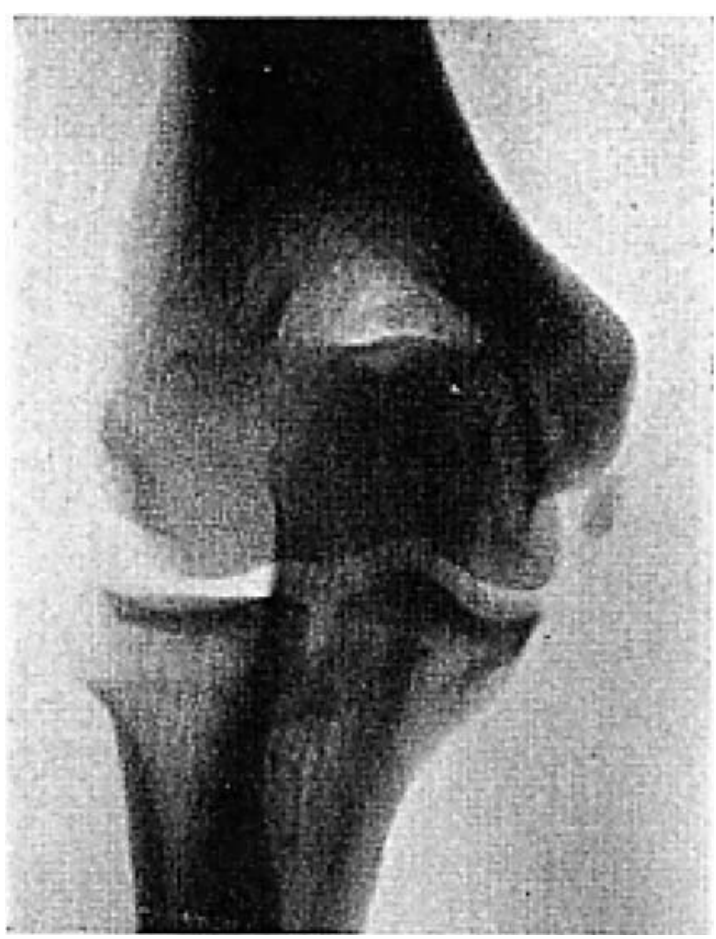

Fig. 10 Ossicle in the ligamentous tissue.

within the joint. I am quite sure that these deposits are purely the result of chronic strain and probably take years to develop. In many instances there are no symptoms. When these deposits cause irritation of the ulnar nerve they can be removed with success. Identifying these small masses of bone in the ligamentous tissue, and dissecting them free, will relieve symptoms in most cases. On exposure of the joint, care must be taken to avoid injury to the ulnar nerve. As a rule there is nothing to be seen or palpated; however, the ossicles can be located by the use of a long skin needle puncturing the ligamentous tissue and locating the osseous mass. It can then be dissected free. I never attempt to close the hiatus in the ligamentous tissue [2]. (Fig. 10.)

\section{Shoulder}

For many years I have been able to demonstrate a lesion in the shoulder of professional pitchers and other baseball players which I do not think one sees in other persons. Because of the excessive use of the arm and the tremendous pull on the posterior capsule and the triceps tendon, a deposit of bone develops on the posterior inferior border of the glenoid fossa which is strikingly similar to the osteoarthritic deposit that one sees in older people. The location of this deposit is such that it produces an irritation of the capsule and of the synovial membrane. This exostosis or deposit also produces an irritation of the circumflex nerve with referred pain to the deltoid region. (Fig. 11.) The symptoms are local discomfort and sensitiveness on palpation in the posterior shoulder plus referred pain to the deltoid region. When the player attempts to throw hard after one or two innings, he suffers so much pain and discomfort that he is unable to continue in the game.

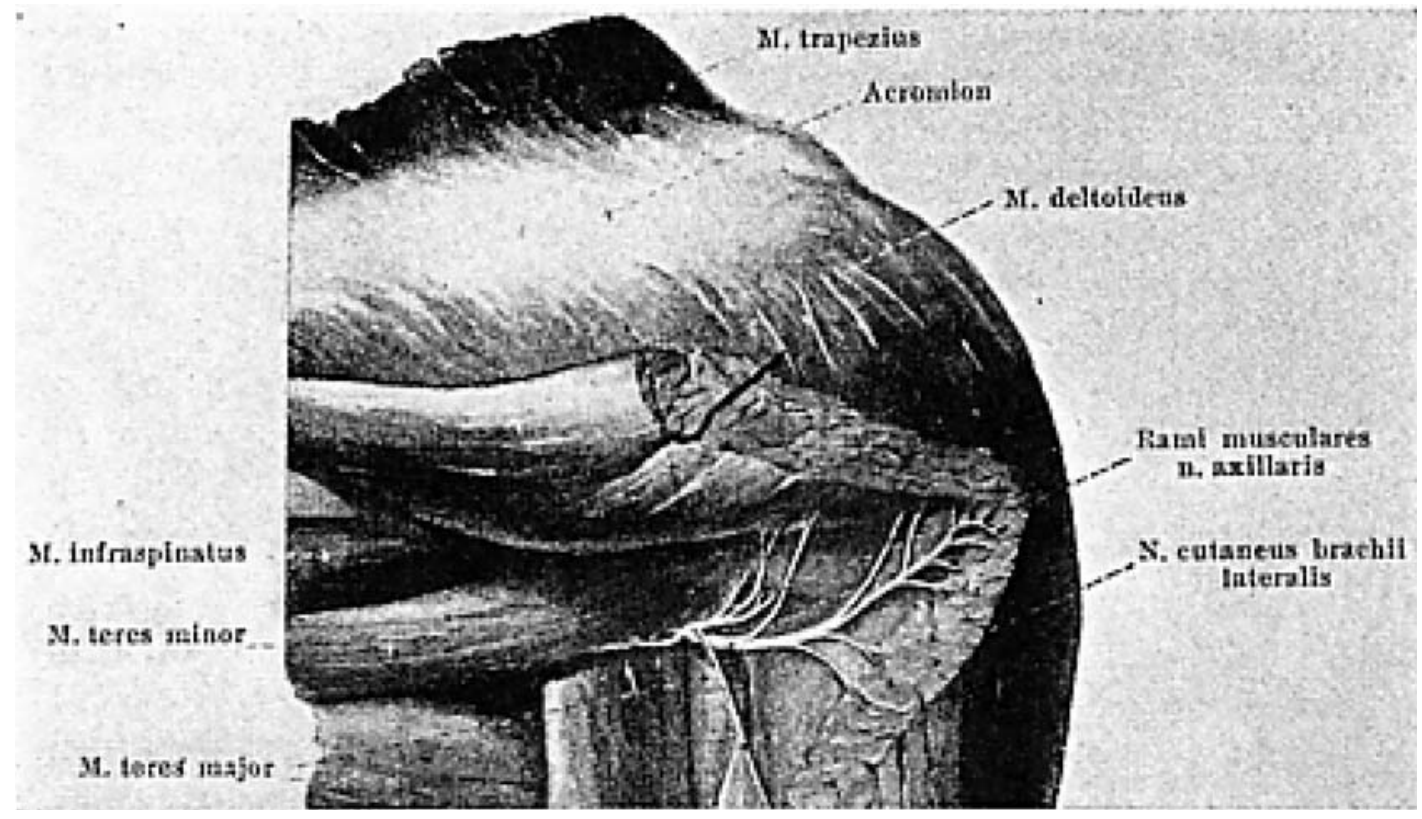

Fig. 11 Circumflex nerve in proximity to exostosis. (From: Spalteholz, W. Hand Atlas of Human Anatomy, vol. 3, p. 760. Philadelphia, 1923. J. B. Lippincott Co.) 
Fig. 12 Exostosis of the inferior border of glenoid.

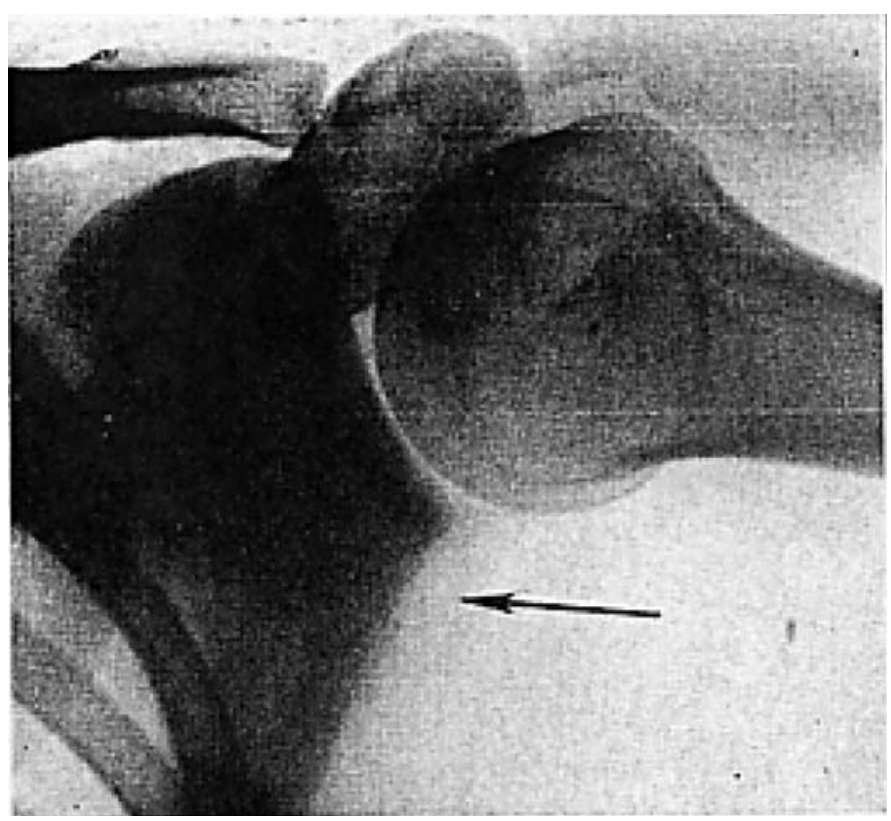

Fig. 13 Exostosis of the inferior border of glenoid.

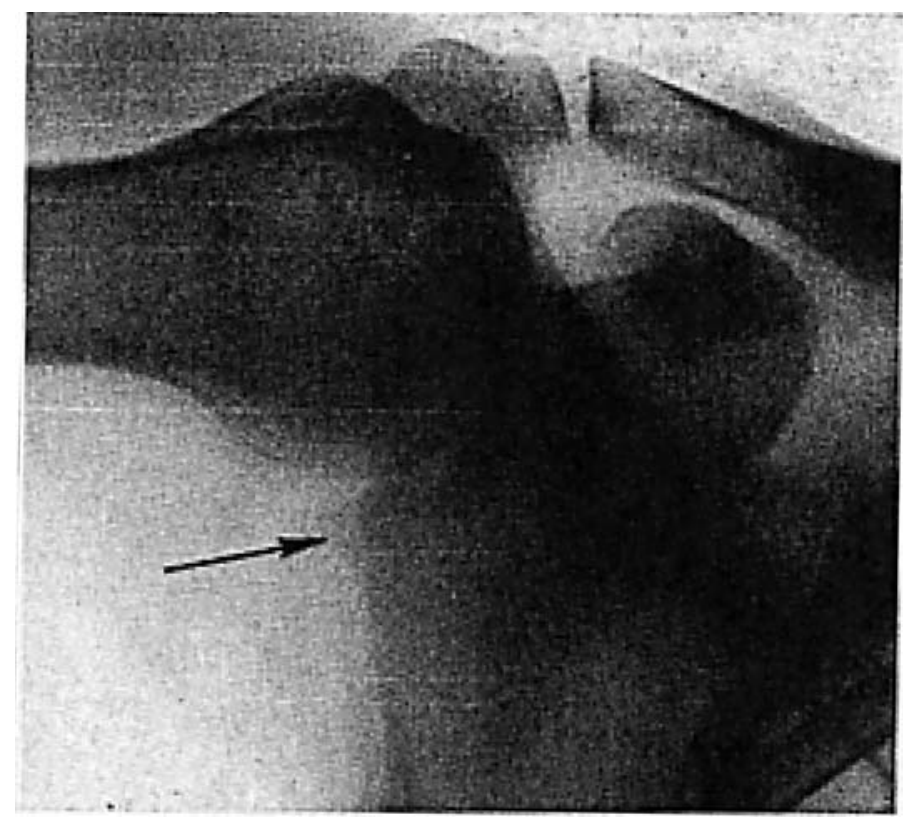

Careful observation of the position of the arm and the arc of motion helps to prove the cause of disability. On observing a professional pitcher as he "warms up," throwing a ball easily while he gradually increases its speed, one will notice that when he begins to "stretch" he seems to be trying to throw his arm at the catcher. After the warm up, he reports that his arm is "loose" and feels fine. This statement is true, because to be effective his arm must be relaxed at the finish of the delivery. When the arm is "tight" the muscles are spastic and effectiveness is lost. One does not have to draw on the imagination to appreciate the tremendous pull on the posterior and anterior shoulder as the weight of the arm is swished forward in a flail-like motion. This constant strain tends to cause the development of a pathologic process the posterior and inferior margin of the glenoid fossa which is strikingly similar to the formation of exostosis in other joints that have been subjected to excessive strain and overuse. Fortunately, this is not a constant disability of the "veteran." I have examined professional pitchers who, after twenty years of active baseball life, show no such deposits, on the other hand I have seen youngsters of twenty or twenty-one years in whom these same changes have already occurred. Symptoms may develop gradually with an increase in severity or 
may have a sudden onset. The pitcher may be able to tell the pitch and the day when he suffered this sudden pain in the back of his shoulder. The pain persists and he can throw "hard" only a few innings, then the local posterior pain plus the referred pain to the deltoid region becomes so great that his arm feels "dead."

It is a common observation that deposits in other joints may exist for a considerable time, causing no inconvenience. For instance, when a sneeze is said to produce an attack of lumbago, the roentgenogram may show deposits on the vertebrae which have been developing for years. I do not believe one can say that a sudden strain is responsible for the lesion I am attempting to describe. (Figs. 12 and 13.)

The treatment of the exostosis or deposits in this part of the shoulder is difficult, and it is distinctive of the baseball player. It causes no pain or discomfort for normal function of the shoulder, not even in throwing a baseball at moderate speed. Symptoms are produced only when the baseball is thrown hard. Therefore, it is not a question of

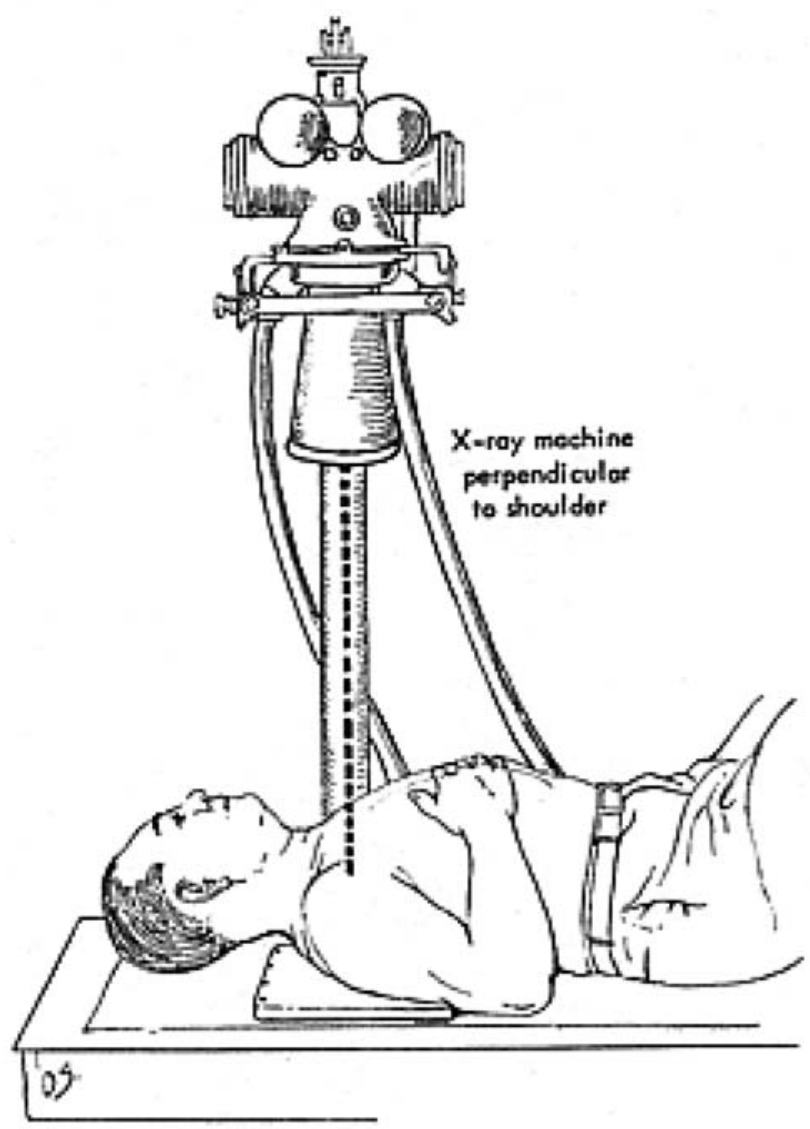

Fig. 14 The exostosis or deposit in the posteroinferior region of glenoid cannot he identified by the ordinary anteroposterior or posteroanterior view of the shoulder. I am grateful to our x-ray technician Mr. W. Ross Mitchell, for development of the technic having the shoulder perform a normal function but of rehabilitating it to perform again the abnormal function that produced the pathologic process. (Fig. 14.) My experience is that operative treatment is not satisfactory and, therefore, not advised.

\section{Bursitis}

Acute traumatic bursitis is a common complaint which responds well to rest and local heat.

Calcium deposits in the bursae and the supraspinatus tendon are not common. I can recall only one instance of a deposit of long duration which required operation. The patient made a complete recovery and he continued to be an effective pitcher.

Chronic traumatic bursitis with a thickening of the subacromial bursa has been observed on numerous occasions. The symptoms are local discomfort and at times crepitus. This is a disabling lesion which does not respond to local or operative treatment. I have explored this type of

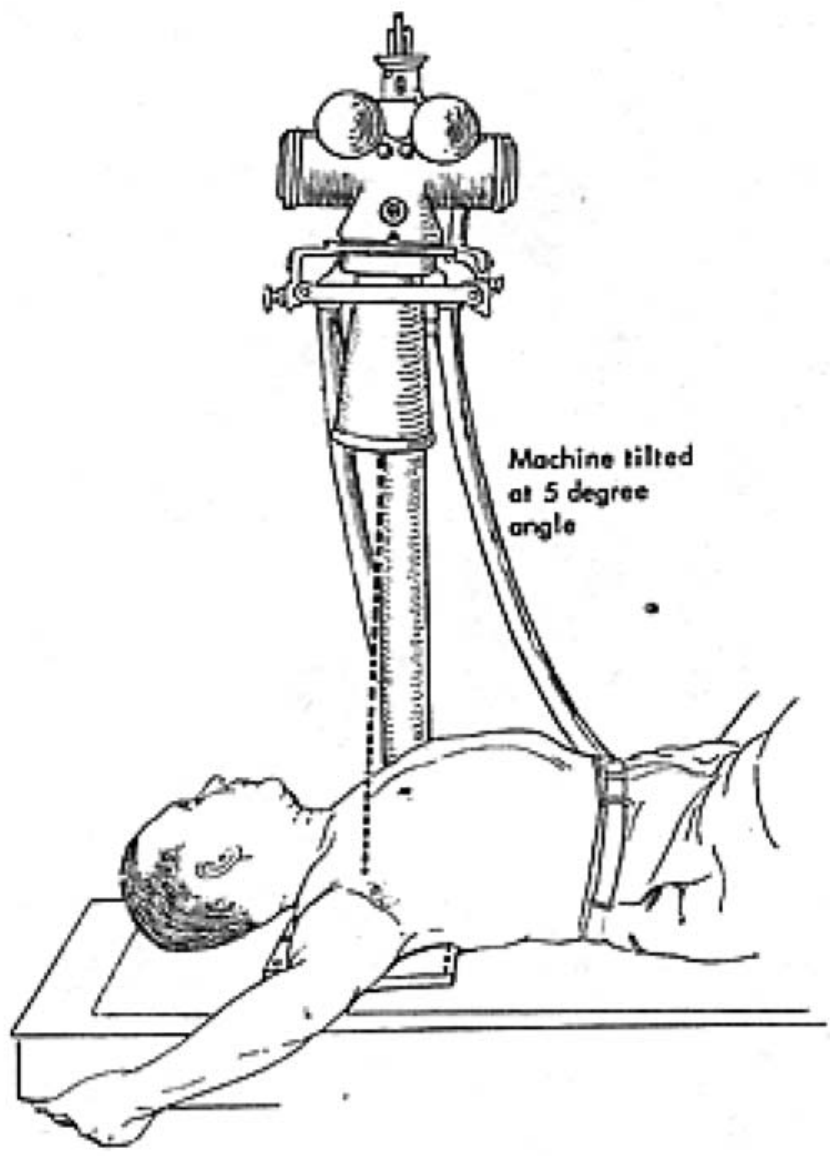

shown. External rotation of the humerus with tilting of the x-ray tube about 5 degrees is the position which rotates the head of the humerus and the glenoid to a position which throws the thickened area in relief. (From: Bennett. G. E. [1].) 
Fig. 15 Acute traumatic separation of the supraspinatus tendon.

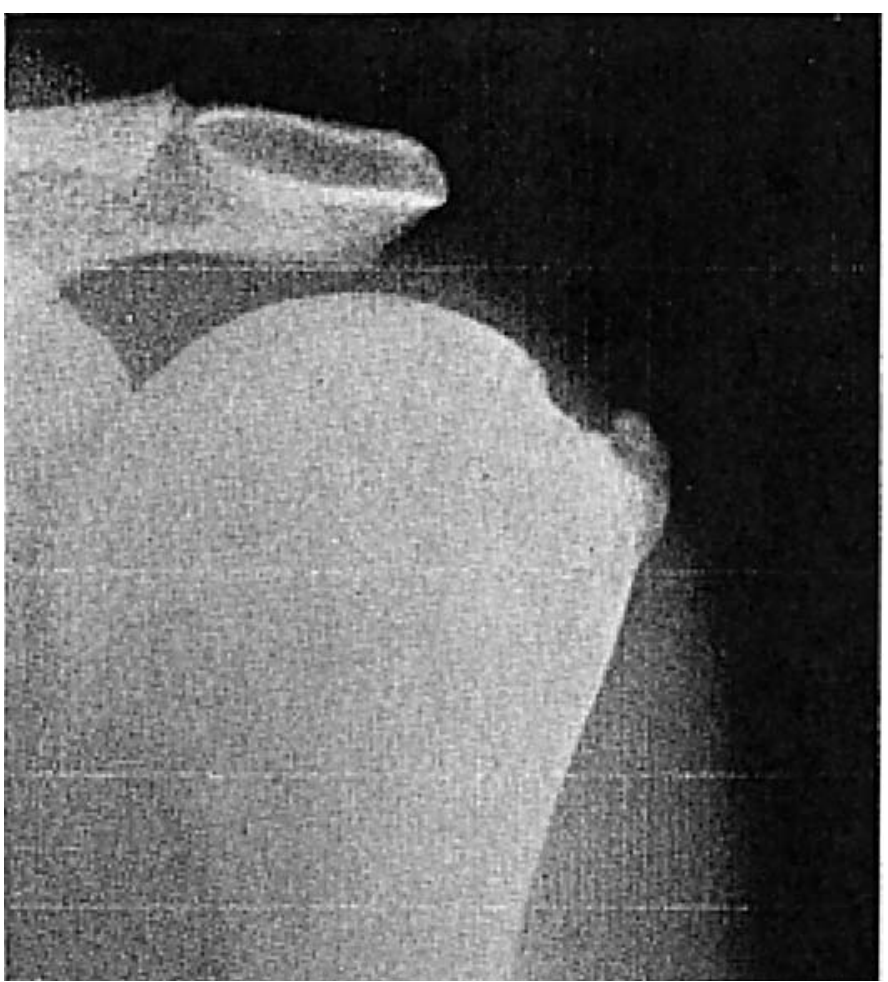

shoulder against my better judgment at the request of patients who pleaded for an operation, and have found a thickened membrane with rugae. A complete excision has not been successful in restoring function.

\section{Fraying of the Tendon}

The supraspinatus tendon is subject to great strain and snubbing by the head of the humerus, as a result fraying of the tendon occurs in proximity to the head of the humerus and the tuberosity. It is a lesion which is seen most often in the veteran pitcher and is characterized by pain in the region of the tuberosity and the anterior shoulder. I have explored this type of lesion at the request of patients to find a smooth superior surface of the tendon, but upon making a linear incision of the tendon, a fraying of the deep structure is revealed. This, also, is a pathologic process which does not respond to surgical or other treatment.

Tearing of the supraspinatus is rare. I am reporting two such cases in detail. In one case the player was injured when he slid into second base and grasped the bag with his pitching arm. On exploration it was found that a small portion of the tendon was pulled from the tuberosity and created a mass. (Fig. 15.) Excision of this mass of macerated tendon and the suturing of the tendon produced a very satisfactory result. The patient, who was twenty-seven years of age, was able to pitch effectively for several years afterward.
The second case was that of a thirty-four year old player who had pitched in the minor leagues since he was eighteen years of age, and in the National League for eight years. His description of his symptoms indicated that for a considerable time he had had pain similar to that caused by a frayed tendon. One year prior to his visit to me in 1948, he had thrown a baseball hard and had had a sensation of a snap in his shoulder with intense pain. He had not been able to pitch since. The operative findings were as 1 had suspected, a frayed tendon which had suddenly torn. The result was obvious. 1 repaired the torn portion but could not repair the fraying of the deep surface of the tendon. He had worn out the tendon, and was never able to return to the mound. (Fig. 16.)

It will be noted that the $\mathrm{x}$-ray findings are almost identical in these cases. In the first case the lesion was traumatic and in a younger man; the result was satisfactory. In the second case the patient was a veteran who had worn out his supraspinatus tendon; the result, as could be expected, was a failure so far as his being able to continue as a ball player but satisfactory for normal function.

The biceps tendon is a structure which at times presents symptoms but not as frequently as the supraspinatus or the infraspinatus tendons. At times it becomes frayed. Also, it may become partially dislocated. One patient with this complaint consulted me and presented the typical syndrome which has been described by DePalma [4]. The player had no pain when throwing a baseball, only when 
Fig. 16 Chronic fraying of the supraspinatus with rupture of the tendon.

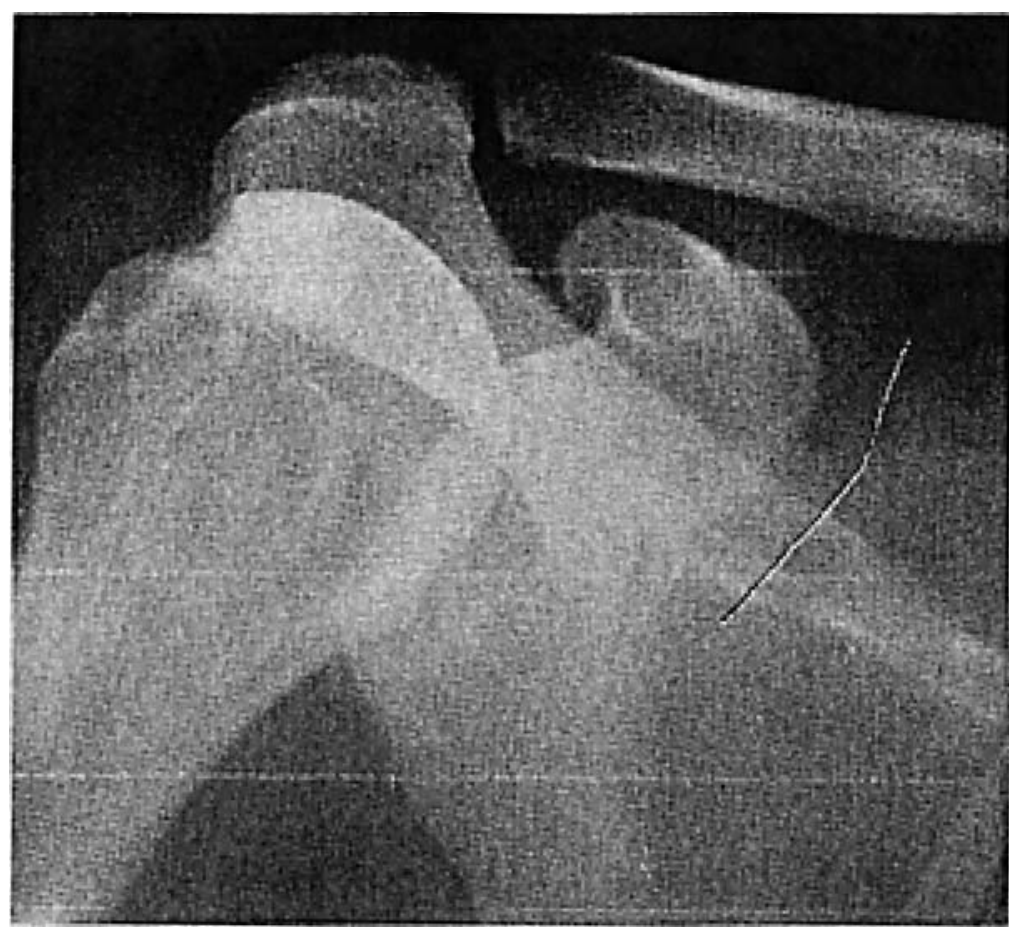

batting. As this player resided in Philadelphia, I referred him to Dr. DePalma who operated, found a partially displaced tendon and performed a fixation via his stapling procedure. The result was satisfactory and the player was able to return to active play.

\section{Loose Bodies}

Loose bodies in the shoulder joint are rare. I can recall one college shortstop who complained of intermittent catching and swelling of the shoulder. I operated, exploring through the axilla, and removed the loose body with a very satisfactory result. (Fig. 17.)

\section{Scapula}

Players, particularly pitchers, often complain of marked discomfort in the region of the infraspinatus muscle. This may be caused by simple myositis and may be transient. Dr. George Resta of Washington is of the impression that it also may be due to an irritation of the suprascapular nerve. A glance at Figure 18 makes this deduction rational. The suprascapular nerve supplies the supraspinatus, the infraspinatus and to a lesser extent the posterior shoulder. If one considers the excursion of the scapula forward in the throwing of a baseball, it seems quite possible that this nerve could be irritated as it passes beneath the base of the acromion where it joins the spine of the scapula.
I have requested Dr. Resta to describe his method of treatment, which follows:

"As you already know, I have been injecting the suprascapular nerve since 1947. The technique I employ is to lay the individual face down, with the extremity elevated, the point of insertion being beneath the acromion at an oblique angle, a 22 gauge, three inch needle being used. Upon contact of the nerve, the patient experiences pain. This is usually encountered following the insertion of the needle to about two inches.

"From 1947 to 1952 Novocaine was used; from 1952 to date, steroids (Hydrocortone $50 \mathrm{mg}$. per cc. employed by me) were used. Usually one, never more than two cubic centimeters of Hydrocortone were used. I have found one injection to be sufficient.

"The post-injection therapy is simple. The individual is instructed to use the arm to full capacity the following day.

"I have treated thirty-two baseball players since 1947."

The injection of anesthetics into trigger points of painful spastic muscles is an old treatment which is often successful.

In conclusion, I take this opportunity to make a statement that may be questioned. It is my opinion that the throwing of a baseball side arm produces less trauma to the vulnerable superior and anterior structures of the shoulder than the throwing of a baseball by so-called overhand delivery.

The overhand delivery snubs the supraspinatus more than the side arm delivery. With the latter method the head 
Fig. 17 Loose body in the shoulder joint.
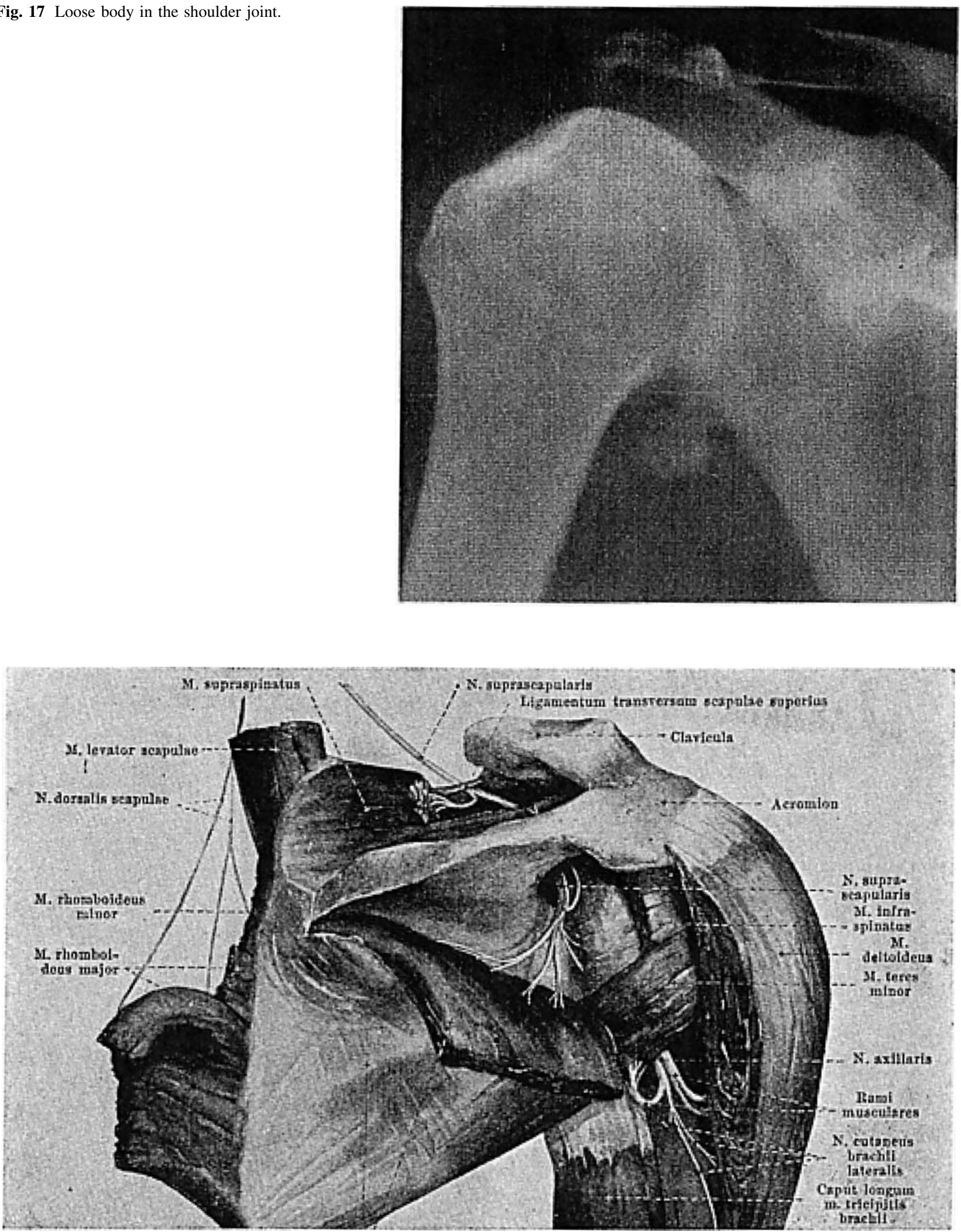

Fig. 18 Demonstrating the location of the suprascapular nerve. (From: Spalteholtz, W. Hand Atlas of Human Anatomy, vol. 3 , p. 746. Philadelphia, 1923. J. B. Lippincott Co.) 
of the humerus glides laterally and not in the semi-perpendicular position.

It is a very definite fact that veteran pitchers gradually lower the delivery from overhand to three-quarters and then side arm. The reason must be comfort. When this statement is made to a manager or coach he will remark that a baseball cannot be thrown as hard from side arm as from overhand. Nevertheless, the fastest pitcher in the game is reported to have been Walter Johnson, who was strictly a side arm pitcher.

On many occasions I have suggested this type of delivery to pitchers who have had the supraspinatus syndrome, with satisfactory results.

I cannot mention names but a few years past an overhand pitcher consulted me. When I asked him if he had pain in the shoulder when he used a side arm delivery, he answered that he did not. My statement to him was: "You are now a side arm pitcher." The result was that he pitched successfully for several years, occasionally making an overhand delivery.

The side arm delivery does not lessen the pull on the posterior shoulder.

\section{References}

1. Bennett, G. E. Shoulder and elbow lesions of the professional baseball pitcher. J. A. M. A., 117: 510-514, 1941.

2. Bennett, G. E. Shoulder and elbow lesions distinctive of baseball players. Ann. Surg., 126: 107-110, 1947.

3. Shands, A. R., JR. The regeneration of hyaline cartilage in joints. Arcb. Surg., 22: 137-178, 1931.

4. DePalma, F. Symposium on orthopedic surgery; bicipital tenosynovitis. S. Clin. North America, 33: 1693-1702, 1953. 